\title{
A Walloon spatial simulation model of risks in environment and health
}

\author{
N. Stephenne ${ }^{1}$, S. Remy ${ }^{1}$, S. Eloy ${ }^{1}$, F. Stassen ${ }^{1} \&$ J. Defoux ${ }^{2}$ \\ ${ }^{1}$ ISSeP, Institut Scientifique de Service Public, Belgium \\ ${ }^{2} S P W$, Service Public de Wallonie, Belgium
}

To develop a spatial and quantitative analysis of health problems related to the environment is a challenging exercise combining different factors of risk and many actors. Using geographic information systems (GIS), multi-criteria decision theory and fuzzy logic, our risk simulation model aims to support decision makers to better understand, analyse and manage the health of the population in relation to environmental pollutions. This tool will be used within an exchange platform between the responsible authorities such as data providers and experts in health and environment to set up priorities in managing the complex system of health and environment at the level of the Walloon Region. This paper describes the purpose of this simulation model of risks, its technical development with a first set of simulation data and the proposed way of using this tool by authorities.

Keywords: geographical information system, simulation model, Walloon Region, environment, health.

\section{Introduction}

Understanding the links and interrelation between health and environment is a challenge because of the complexity of the system integrating these two aspects of citizens' life. Dealing with individual or compound effects of pollution, contamination, or hazards, in time and space is particularly broad and challenging (Koren and Bisesi [1]). This paper describes a simulation tool developed to improve our understanding of this complex system. This tool aims above all to support decision making in health and environmental management.

Decision support systems (DSS) were first developed in management science in the late 1970s to provide a framework for integrating database management systems, analytical models and graphics in order to improve decision-making processes (Longley et al. [2]). Rather than producing solutions to problems, 
decision support provides data and predictions to inform about the reality. The DSS has been extended to the spatial context in the development of spatial decision support systems (SDSS). The Geographical Information Systems (GIS) technology is used to combine the digital data and perform geospatial analysis to integrate the different data in a common analytical system. SDSS are using GIS processing in association with optimization methods of weighting different criteria (Multi-criteria decision analysis) [3]. On the contrary of the simple binary techniques (good or bad), the weighted suitability models classify the layers on a relative scale and multiply each layer by its relative importance. While decision support is an important function of a GIS, GIS software has only recently integrated DS function in its tool box.

According to Andrienko and Andrienko [4], the process of decision making comprises three major phases: intelligence, design and choice. While situation analysis, problem recognition, and finding possible solutions can mainly be addressed by scientists in developing simulation tools, the third phase can only be carried out by decision makers. The tool developed for the Walloon region and described in this paper proposes that scientists and policymakers work together within the development of the simulation tool in a real participative approach. Multicriteria model using GIS technologies can also be seen as a communication tool between scientists and policy makers, between technologists and field experts. This paper presents the methodology of the first version of a simulation model of risks in Environment and Health for the Walloon authorities: (i) assumptions, (ii) risk factors (pollution in environmental components and vulnerable population), (iii) data, (iv) processing chain and (v) first simulation results. This technical phase will be followed by a consultation of authorities to improve the conceptual model, to agree on the results, and to identify priorities as well as potential mitigation measures.

\section{Model development}

\subsection{Assumptions}

Combining Geographic information systems (GIS), multicriteria decision theory, fuzzy logic in a simulation model creates opportunities to better represent, understand, analyse a system to support the management of this system. Only a spatial quantitative simulation model allows a holistic representation of health risks related to the degradation of population's living conditions. With this model, we can generate "what-if" scenarios exploring the influence of single or groups of variables on the overall system. Based on clear assumptions, modelling can help for prioritization of investment and simulation of political decision impacts. Simulation emphasizes the interactions among the components of the system and takes into account the quantitative effect of each risk factor.

ISSeP started to work on this integrated approach in cooperation with the Environmental Services of the SPW. These services are building databases and metadata to monitor pollutions on the Walloon territory. In line with the Inspire EU directive, there is a need toward data harmonization. Harmonization will 
contributes to this study combining various risk factors into a common system. Collaboration with both environment and health services is mandatory. Modelling interrelations between health and environment is a challenging initiative assuming the collaboration of various services and actors.

The spatial simulation tool models risks on health related to environmental pollutions in air, soil and water (3 environmental components). The Risk is the result of the following equation multiplying the Probability of Danger (pollutions in air, soil or water) and the Exposure to human health in eqn (1):

$$
R=P(D) \times E
$$

Pollutions in one of the three environmental components are added to each other in a total probability of danger. The multiplication between danger and exposure is a general hypothesis in all risk models. The additive association will be discussed with stakeholders for later versions.

Specific technical hypotheses are needed to represent this health risk of pollution at the scale of the Walloon Region. They are clearly specified below to increase the transparency between the scientists and the decision makers:

1. The model is an abstraction in two dimensions of the risk to health in relation to environmental pollutions through air, soil and water.

2. The pollutions are spatially explicit and can be represented by variables/ proxies using dataset provided by the responsible authorities.

3. The first list of indicators is proposed by scientists based on literature review and will be discussed in the decision making process (see section 3) with data producers and stakeholders.

4. The resolution chosen to address the risks at the Walloon region is $100 \mathrm{~m}$ pixel size which corresponds to a cartographic scale of 1:100 000 . The abstraction of risk is then associated to each cell of $100 \times 100 \mathrm{~m}$. This resolution allows a good discrimination of local effects in relation to population distribution. Moreover, resolution choice is related to the data availability of population density dataset provided by the European Environmental Agency.

5. The development within a GIS needs an unambiguous and common spatial reference of the stored information. The spatial reference system is given by the coordinate system used by Walloon administration which is the Lambert 72 in Belgium.

6. Decision rules involve combining one or more criteria into a composite index [5]. A criterion can be measured and evaluated, in our case each environmental component is considered as a criterion. The factors are the specific pollutants or indicators contributing to each criterion.

7. In order to combine the different layers in the same multi-criteria model, all factors should be measured on a grid raster format. In GIS, there are two digital map representation techniques: vector and raster. With vector representation, the boundaries or the course of the feature are defined by a series of points that, when joined with straight lines, form the graphic representation of that feature (points/lines or 
polygons). The points themselves are encoded with a pair of numbers giving the $\mathrm{X}$ and $\mathrm{Y}$ coordinates in the latitude/longitude system. The attributes of the features are stored in a database linked to the spatial file by a unique identifier. With the raster dataset the graphic representation of features and the attributes they possess are merged into unified dataset; a mesh of grid cells in which we record the condition or attribute of the earth surface at that point. To combine these two formats, vector datasets are transformed in raster format (rasterisation) based on the cell resolution defined (see section 2.4.).

8. GIS must have a uniform range of values. After spatial transformation of layers; their continuous range of values has to be transformed in standardized units to be associated in the multi-criteria model. Using fuzzy membership function, each pixel value is standardised to a 0-1 range of values. In this first feasibility phase the linear function has been chosen, the use of sigmoidal or other function could be discussed with the stakeholders later on if appropriate.

\subsection{Risk factors}

Geographic representation of health risks related to environment relies heavily on the understanding of underlying causes of pollution. During the last two year, the potentially contaminated fields and their sources of pollution have been identified after discussion with respective experts in a three steps approach:

- Inventory and collection of databases and metadata relevant in this context and available at the level of the Walloon region

- Identification of experts and meetings with them for a detailed presentation of project objectives and discussion of risk factors

- Hierarchisation of risk factors based on a literature review and analysis of similar studies in neighbouring countries [6-9].

Table 1 identifies the indicators potentially relevant for understanding accumulation of environmental pollutions. Completion or not of this list of indicators, integration and choice of factors per criteria and spatial or numerical conditions attached to this factor will be thoroughly discussed with the stakeholders during the second phase of this project (see section 3).

This list includes pollution by chemicals in soil and air, plus another category called "other pollution" (see Table 1). The water component is not included in this version because water distribution is considered as highly controlled in the Walloon Region. The "other pollution” category includes radon emission, noise and electromagnetic fields. They are respectively at risk for specific pathologies such as cardiovascular diseases for noise $[10,11]$ and lung cancer for the radon emission [12]. This category can be related to another environmental component in later version. For the soil component, we distinguish two factors; soil quality and sources of pressure which can define a degraded landscape in terms of soil pollution. The air pathway integrates three factors; the air quality summing the average concentration for 5 main pollutants, the sources of mobile and stationary pollutions which are respectively linked to transport sector and industrial emissions. 
Table 1: Indicators of environmental pollution.

\begin{tabular}{|c|c|c|c|}
\hline $\begin{array}{c}\text { Environ- } \\
\text { mental } \\
\text { components } \\
\end{array}$ & $\begin{array}{l}\text { Pollution } \\
\text { criteria }\end{array}$ & Pollutant factor name & $\begin{array}{c}\text { Fuzzy and } \\
\text { spatial } \\
\text { conditions } \\
\end{array}$ \\
\hline \multirow[t]{15}{*}{ Soil } & \multirow{7}{*}{ Soil quality } & Chromium in surface layers & $1-81 \mathrm{mg} / \mathrm{kg}$ \\
\hline & & Mercury in surface layers & $0.05-0.4 \mathrm{mg} / \mathrm{kg}$ \\
\hline & & Zinc in surface layers & $1-395 \mathrm{mg} / \mathrm{kg}$ \\
\hline & & Lead in surface layers & $3-237 \mathrm{mg} / \mathrm{kg}$ \\
\hline & & Nickel in surface layers & $1-73 \mathrm{mg} / \mathrm{kg}$ \\
\hline & & Copper in surface layers & $1-38 \mathrm{mg} / \mathrm{kg}$ \\
\hline & & Cadmium in surface layers & $0.1-2.7 \mathrm{mg} / \mathrm{kg}$ \\
\hline & \multirow{8}{*}{$\begin{array}{l}\text { Local } \\
\text { pollutions }\end{array}$} & Roads & 100 m Buffer \\
\hline & & Airports & 100 m Buffer \\
\hline & & Mine heaps & 100 m Buffer \\
\hline & & SAR (potential polluted sites) & 100 m Buffer \\
\hline & & Waste landfield (COSW) & 100 m Buffer \\
\hline & & Seveso facilities & 2 km Buffer \\
\hline & & Past industries (VDM) & 2 km Buffer \\
\hline & & IPPC facilities & 2 km Buffer \\
\hline \multirow{9}{*}{ Air } & \multirow{5}{*}{$\begin{array}{l}\text { Ambient } \\
\text { air quality }\end{array}$} & PM10 (5 years mean) & $14-30 \mu \mathrm{g} / \mathrm{m}^{3}$ \\
\hline & & PM25 (5 years mean) & $11-25 \mu \mathrm{g} / \mathrm{m}^{3}$ \\
\hline & & $\mathrm{NO}_{\mathrm{x}}(5$ years mean $)$ & $4-34 \mu \mathrm{g} / \mathrm{m}^{3}$ \\
\hline & & $\mathrm{SO}_{2}$ (5 years mean) & $0.8-30 \mu \mathrm{g} / \mathrm{m}^{3}$ \\
\hline & & Ozone ( 5 years mean) & $32-57 \mu \mathrm{g} / \mathrm{m}^{3}$ \\
\hline & \multirow{2}{*}{$\begin{array}{l}\text { Stationary } \\
\text { sources }\end{array}$} & IPPC facilities & 2 km Buffer \\
\hline & & City limits & / \\
\hline & \multirow{2}{*}{$\begin{array}{l}\text { Mobile } \\
\text { sources }\end{array}$} & Regional road network & 100 m Buffer \\
\hline & & Airports & 1 km Buffer \\
\hline \multirow{3}{*}{$\begin{array}{l}\text { Other } \\
\text { pollutions }\end{array}$} & Radon & Radon concentration in dwellings & $22.7-200 \mathrm{~Bq} / \mathrm{m}^{3}$ \\
\hline & Noise & $\begin{array}{l}\text { Noise intensity near mobile } \\
\text { sources, main cities and facilities }\end{array}$ & $0-101 \mathrm{~dB}$ \\
\hline & $\begin{array}{l}\text { Electro- } \\
\text { magnetic } \\
\text { fields }\end{array}$ & Mobile phone antenna density & $0-7.8 \mathrm{~V} / \mathrm{m}$ \\
\hline
\end{tabular}


In order to calculate the risk to human health, we have to integrate environmental pollution with population taking into account sensitive types of population. Table 2 describes the two indicators; demography and vulnerable infrastructures.

Table 2: $\quad$ Indicators of population.

\begin{tabular}{|l|l|}
\hline Indicator & Factor name \\
\hline General population & Density \\
\hline \multirow{5}{*}{ Vulnerable population groups } & Unwealthy communes \\
\cline { 2 - 2 } & Residential camping \\
\cline { 2 - 2 } & Sports and leisure area \\
\cline { 2 - 2 } & Children: schools \\
\cline { 2 - 2 } & Infants: childcare \\
\cline { 2 - 2 } & Elderly: Nursing home \\
\cline { 2 - 2 } & Hospitals \\
\hline
\end{tabular}

\subsection{Data}

In the modelling process, an important step is the collection and the assessment of quality, comprehensiveness and shortcomings of existing information. In this study, a large detailed inventory of the databases containing pollution information has been carried out in the last two years. For each dataset, a file describes the following characteristics: title, description, coverage, date of production, update frequency, scale, unit, producer, accessibility conditions. Each dataset is analysed in terms of relevance to represent one of the risk factors.

Data producers are the relevant experts in their specific fields. The main contributors are:

- The Scientific Institute of Public Services (ISSeP): electromagnetic fields and ambient air quality;

- The Historic Centre of Science and Technology (CHST): past industries ;

- The governmental public services of the Walloon Region: current stationary sources, mobile sources (regional road network and airports), local soil pollution (waste landfields, SAR), drinking water quality, noise, residential campsites, sources and fountains;

- $\quad$ The Federal Agency for Nuclear Control (AFCN): radon in dwellings;

- The Walloon Institute for Evaluation, Prospective and Statistics (IWEPS): economic indicator

- Environmental European Agency (EEA) for the population density dataset [13].

These responsible authorities will be included in the decision building process that will start in the next few months (see section 3). The results of this feasibility study will be demonstrated to these experts through consultation, workshops or individual meetings. Their level of agreement on, respectively, the 
assumptions, the list of risks factors, the spatial and numerical conditions of integration and the results of the model will be measured and discussed to improve this model. Results are to be considered as illustrative of the method.

\subsection{Processing chain}

GIS technology with Arc GIS software (CESRI) combines data into a common system. The present released model uses as input more than 40 spatial data layers ranging from land use- land cover, environmental conditions of soil or air, presence of population, transport network, ...

As detailed in the assumptions (see section 2.1), integrating various dataset into a common GIS implies to standardize and geo-reference these inputs. The four processing steps are: (i) spatial transformation (projection and delimitation of the extent), (ii) conversion in grid data (raster) to facilitate the mathematical operations on criteria (iii) normalization of values according to a fuzzy logic linear interpolation, and (iv) overlapping criteria without distinguishing weight. Figure 1 shows these four steps with illustrations with our simulation dataset.

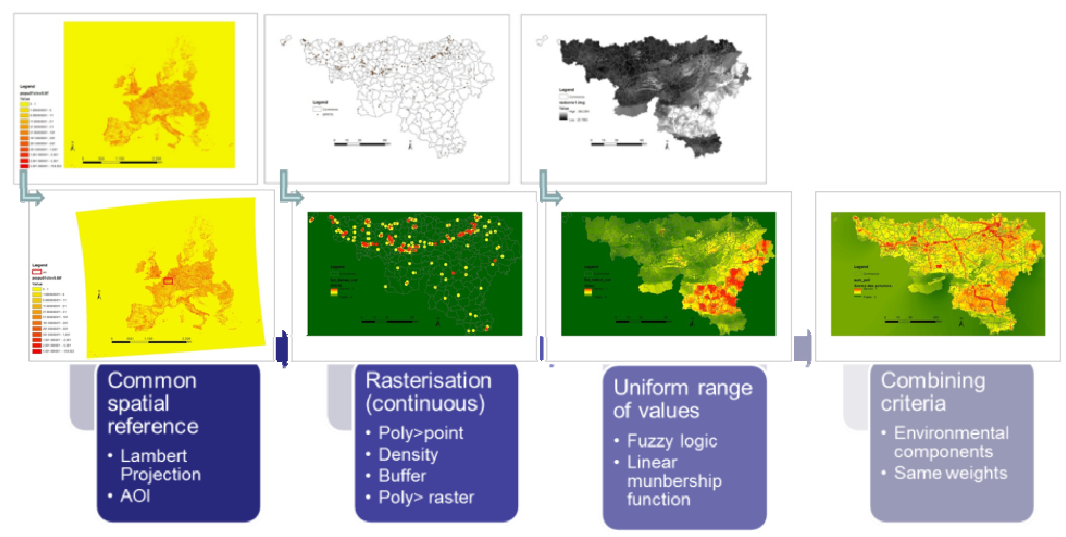

Figure 1: Processing steps in a spatial model of risks to health related to environmental pollutions.

The first step defines the Area of Interest (AOI), by clipping each dataset to the same extent. This spatial transformation is carried out after the geographical projection. All datasets coming from Walloon producers are provided in Lambert 72. Population density layer has been transformed from European Terrestrial Reference System ETRS89 (geodetic datum proposed by Inspire guidance documentation for European datasets) to Lambert 72. As the model has to be used by regional authorities this geographical reference system was mandatory.

The second step combines the transformation in raster format for all vector files (represented by circles in Figure 2) and the proximity calculation (Buffer $100 \mathrm{~m}$ and $1 \mathrm{~km}$ ). For points' dataset (IPCC), a density is calculated within the neighborhood. This number of point per unit of area is measured per circle 
around each cell (2km of radius). For polygons' datasets (VDM, Seveso), a point is derived from each polygon and the same calculation of density is carried out.

The third step refers to the normalization of values. Assumption 8 (see section 2.1) refers to fuzzy logic. Fuzzy membership functions are controlled by four points ordered from low to high on the measurement scale (Figure 3). The first point marks the location where the membership function begins to rise above 0 . The second point indicates where it reaches 1 . The third point indicates the location where the membership grade begins to drop again below 1, while the fourth point marks where it returns to 0 . Points may be duplicated to create monotonic or symmetric functions. This version of the model uses linear functions; sigmoid functions could be used in a later version.

The fourth modeling step is the overlapping of each criteria and the calculation of the total risk. The total risk multiplies the total pollution danger to the vulnerable population. The Boolean overlay and the weighted linear

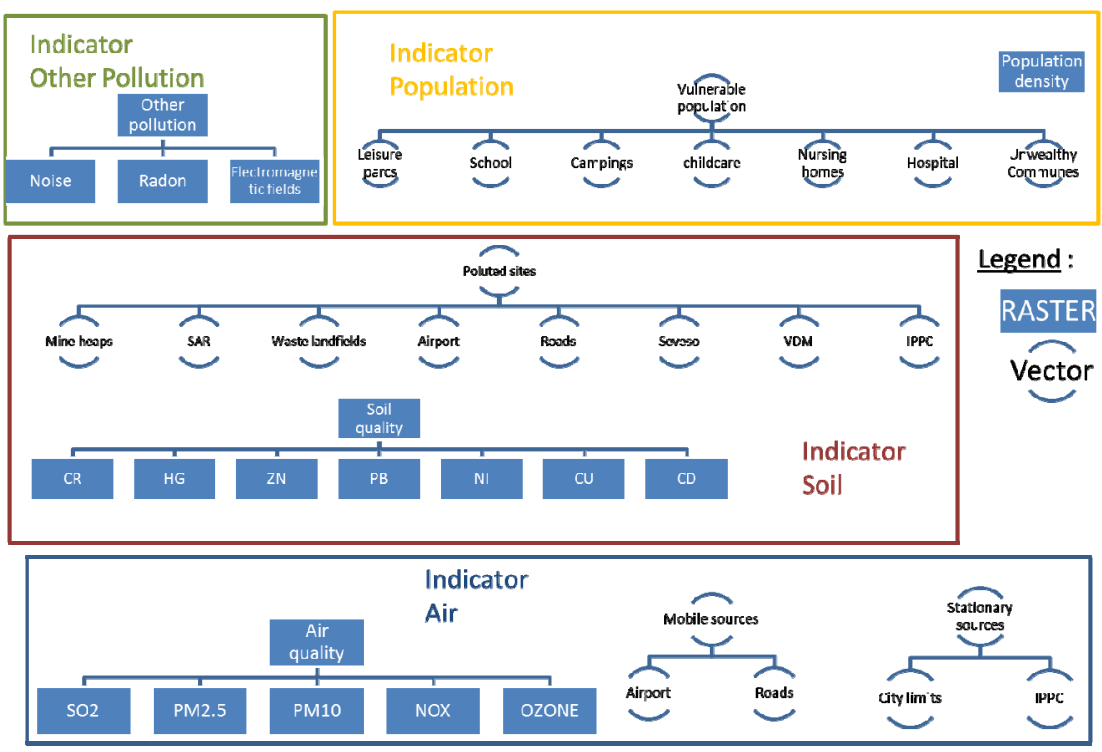

Figure 2: $\quad$ Combination of raster and vector files in risks factors.

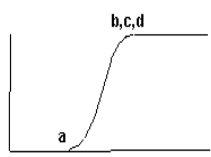

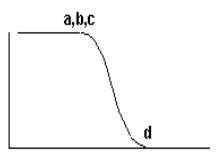

(a)
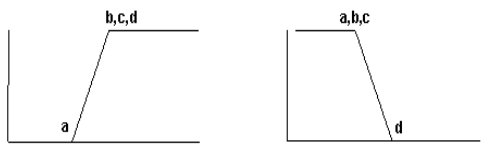

(b)

Figure 3: $\quad$ Sigmoid (a) and linear (b) fuzzy functions for transformation in a uniform range of values. 
combination (WLC) strategies are respectively chosen in the modelling literature. In our WLC procedures, the simplest choice, of equal weights for each criterion, is used as a baseline test in order to increase the understanding of the basic rules of the model, but other combinations defined by a pair wise comparison matrix can be used to build spatial analysis scenarios. Overlaying the dataset with or without identifying weights should be discussed with the stakeholders.

\subsection{Draft results}

The model is currently under development and this paper presents only the methodology of this modelling exercise. This feasibility phase ends up with some initial simulation maps. But this subject is challenging and results need the agreement of responsible authorities. Considering this, figures 4(a), (b) and (c) below do not refer to the reality of the danger and exposure. They only illustrate the resolution and the type of maps that are expected. As stated in the introduction, scientists and decision makers should work together for a better understanding of the environmental health reality. The output of this feasibility phase feeds the next phase, the decision making.

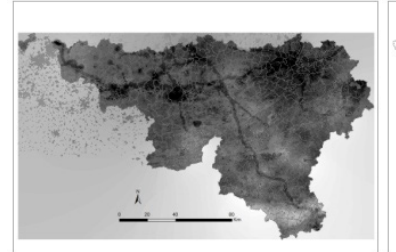

(a)

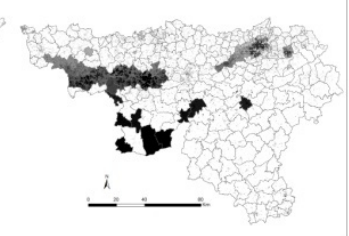

(b)

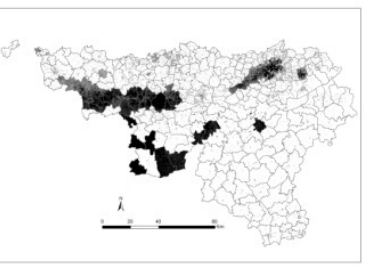

(c)

Figure 4: $\quad$ Pollutions (a), populations (b) criteria and (c) health risk model related to the environment in Wallonia.

\section{Decision making process}

Decision making process comprises three major phases: intelligence, design and choice (Andrienko and Andrienko [4]). The intelligence phase involves situation analysis and problem recognition, the design phase involves finding possible variants of problem solution and the choice phase involves evaluation of the options and selection of the most appropriate ones. Scientists and decision makers need to better communicate to improve the third phase. Going further, scientists could already collaborate with policymakers within the development of their tools in a real participative approach for the two first phases. This integrated approach is attempted in this Walloon project.

IIED [14] has applied participative approach to empower local people to assess endangered environments. In the field of natural risks and vulnerability assessment, local consultation is increasingly adopted to estimate the coping capacities of population (Wisner [15]). Information technologies, GIS and 
remote sensing in particular can also be used as a mean of communication in a participatory approach (Lemma et al. [16]).

Two methods of consultation can be applied in the GIS Decision support approach of the model of health risk related to environment in Wallonia: the consultation and spatial visual analysis. Referring to consultations, specific methodologies have been developed. The Delphi method, proposed by Helmer [17], has become widely accepted by a broad range of institutions as the simplest and most efficient way of collecting knowledge (Olfert et al. [18]). This method synthesizes knowledge from a group of experts through iterative investigation of opinions by means of questionnaires (Greiving [19]).

SDSS multicriteria analyses go a step further in progressively integrating the decision makers within the modelling phase. Through user-friendly interfaces, simulation tools have improved the way to communicate results to a broader audience. These tools can now visualize trade-offs between the prioritization of different users to optimize spatial choices. Interactive visual simulation tools present nearly immediately the alternative scenarios of the spatial multicriteria model. The use of these tools within a network of stakeholders to evaluate the weights of a multicriteria approach could promote better communication between scientists of various backgrounds.

\section{Discussions and conclusions}

The first meeting with the authorities confirmed their interest in the proposed methodology. Most of the data producers want to participate in the consultation. They believe both in the tool as well as in the decision making process to better understand the complex system as well as optimise the transversal management between health and environmental services. The amount of participants and the potential integration of international experts have still to be discussed. The setup of this consultation phase should still be formalised in the next months.

However, several issues arose during the process and can slow down the overall decision making process. Three of these issues are: (i) accessibility to databases, (ii) relevance of these data and (iii) cooperation of all actors. For the first issue, even in this feasibility analysis, we experienced some reluctance from data producer in providing their information. While this phase was mainly requested by the environmental services, we believe that a political agreement on the involvement of all actors from environment but also from health in the decision process should mitigate this issue. For the second issue, the participation of producers doesn't necessarily mean that the data represent correctly the indicators of pollution which are needed in the model. While risk factors will be agreed among the working group, the quality, relevance, completeness of each dataset should be assessed in details. GIS techniques can help in this evaluation (Stephenne and Macdonald [20]). The cooperation requires that, even if some experts are working in the assessment of one specific pollution component, they could judge the overall priorities of criteria without bias. The Delphi method can avoid this human behaviour by providing some guidelines and objective measurement to the agreement. 


\section{References}

[1] Koren H. and M. Bisesi, Handbook of Environmental Health, IV edition, Lewis Publisher, US, 2003.

[2] Longley, P., Goodchild, M., Maguire, D., and Rhind, D., Geographic Information Systems and Science (New York: Wiley), 2005.

[3] Geurs K.T., van Wee, B., Accessibility evaluation of land-use and transport strategies: review and research directions, Journal of Transport Geography, 12, 2, 127-140, 2004.

[4] Andrienko, N. and Andrienko, G., Informed spatial decisions through coordinated views. Information Visualization 2, 4, 270-285, 2003.

[5] Eastman, J.R., Kyem, P.A.K and Tolendano, J, A procedure for Multi Objective Decision Making in GIS under Conditions of Conflicting Objectives, Proceedings of the 4 EGIS Conference, Genova, Italy, 1993.

[6] Maulpoix, A., Dor, R.I.C., Zmirou, D., Potentiel d'exposition de la population à la pollution des sols, pp. 1-65, 2005.

[7] InVs, Soil pollution: from population exposure to public health. Bulletin épidémiologique hebdomaire Hors-série, 461-475, 2008.

[8] Caudeville J., Govaert G., Bonnard R., Blanchard O., Ung A., Bessagnet B., Cicolella A., Construction d'un indicateur d'exposition spatialisé de l'environnement. Air Pur 76, 49-55, 2009.

[9] Kruize, B., Environmental (in)equity in the Netherlands-A case study on the distribution of environmental quality in the Rijnmond region, 2004

[10] Crombie, R., Clark, C., Stansfeld, S.A., Environmental noise exposure, early biological risk and mental health in 9 to10 year old children: a crosssectional field study. Environ Health 10, 39, 2011.

[11] Sorensen, M., Hvidberg, M., Andersen, Z.J., Nordsborg, R.B., Lillelund, K.G., Jakobsen, J., Tjonneland, A., Overvad, K., Raaschou-Nielsen, O., Road traffic noise and stroke: a prospective cohort study. Eur Heart J 32, 737-744, 2011.

[12] Schmid, K., Kuwert, T., Drexler, H., Radon in indoor spaces: an underestimated risk factor for lung cancer in environmental medicine. Dtsch Arztebl Int 107, 181-186, 2010.

[13] Gallego F.J., A population density grid of the European Union, Population and Environment. 31: 460-473, 2010.

[14] IIED, A Trainers Guide for Participatory Learning and Action. IIED Participatory Methodology Series, 267 pp. London, UK, 1995.

[15] Wisner, B. Self-assessment of coping capacity: Participatory, proactive, and qualitative engagement of communities in their own risk management. In: Birkmann, J. (Ed.) Measuring Vulnerability to Natural Hazards, United University Press, 316-328, 2006.

[16] Lemma, T., et al., A Participatory Approach to Monitoring Slum Conditions. In International conference on participatory spatial information management and communication, 7-10 September, Nairobi, Kenya, 2005.

[17] Helmer, O., The Use of the Delphi Technique in Problems of Educational Innovations. Santa Monica: The Rand Corporation. 3499 p, 1966. 
[18] Olfert, A. Greiving, S. and Batista, M. J., Regional multi-risk review, hazard weighting and spatial planning response to risk. Geological Survey of Finland, Special Paper 42, 125-151, 2006.

[19] Greiving, S., Integrated risk assessment of multi-hazards: a new methodology. Natural and technological hazards and risks affecting the spatial development of European regions. Geological Survey of Finland, Special Paper 42, 75-82, 2006.

[20] Stephenne N. and C. Macdonald, Building a spatial decision support system for conflict prevention in the Caucasus, EUR report 22949, 2007. 